\title{
Successful Behavior Change Communication Process to Reduce Postpartum Alcohol Intake
}

\author{
Rajapaksa Hewageegana NS ${ }^{1 *}$ and Samarage $S^{2}$ \\ ${ }^{1}$ Consultant Medical administrator, Sheffield Hallam, UK \\ ${ }^{2}$ Senior Associate Institute of Health Care Policy, UK
}

*Corresponding author: Neelamani S Rajapaksa Hewageegana, Visiting lecturer,

\begin{tabular}{|c|}
\hline Research Article \\
Volume 2 Issue 4 \\
Received Date: July 30, 2019 \\
Published Date: August 22, 2019 \\
DoI: $10.23880 /$ jqhe-16000133 \\
\hline
\end{tabular}

Consultant Medical administrator, Sheffield Hallam, UK, Email: drneelamani@yahoo.com

\begin{abstract}
To implement a Behavior Change Communication process (BCC) and to evaluate its impact on alcohol use of the plantation postpartum mothers (PPM) was the objective of this study. A cross sectional descriptive study using mixed methods. An interviewer administered questionnaire to 452 randomly selected PPM at Assessment (pre-intervention) and after 6 months on 205 PPM who had undergone the BCC.

A self-administered questionnaire administered to randomly select 60 ward staff pre and post intervention to assess the BCC provided to PPM.

Focus groups and in-depth interviews were undertaken with plantation community to understand the behavior of alcohol consumption in the postpartum period. Thirty-five (35) nursing staff (58.5\%) had advise on adverse effects of alcohol to the plantation mothers after delivery in the pre-intervention sample it increased to 57 nurses (95\%) at the post intervention assessment $\mathrm{p}<0.001$. PPM, $63.2 \%$ in the pre-intervention taken alcohol reduced to $19.5 \%$ in the evaluation $(p<0.001)$. The use of alcohol with related to breast-feeding reduced significantly in the post-intervention sample $(p<$ 0.001). BCC can significantly reduce alcohol use of PPM.
\end{abstract}

Keywords: Brest Feeding: WHO: Srilanka

\section{Introduction}

"Behavior Change Communication (BCC)" or "Social and behavior change communication (SBCC)", or also referred as "Communication for Development (C4D)" is based on proven theories and models of behavior change. BCC is an interactive process using communication strategically to promote positive health outcomes through positive behavior changes [1,2].
Breastfeeding and breast milk provide benefits beyond nutrition that are unparalleled by any infant formula. Historically alcohol use has been promoted in Breastfeeding [3]. Alcohol levels in the breast milk are similar to the blood alcohol levels of the mother at the time of feeding [4]. World Health Organization (2001) [5] had shown that the benefits of breastfeeding outweigh the risks of an occasional drink of alcohol. The levels of awareness about alcohol use and lactation is low [6]. 


\section{Journal of Quality in Health Care \& Economics}

\section{Objective}

To implement a Behavior Change Communication process and to evaluate the impact on alcohol use of the plantation postpartum mothers.

\section{Materials and Methods}

\section{Study Setting}

Badulla district is in the Uva province in Sri Lanka. It is located in the southeastern part of the central hill country of Sri Lanka. Its boundaries are Ampara, Kandy, Nuwaraeliya, Matale, Monaragala and Ratnapura districts. In Badulla district the Sinhalese population is $73.5 \%$ of the total, $13.4 \%$ of the population is Sri Lankan Tamils and $7.6 \%$ is Indian Tamils. The balance constitute of Moors, Burghers and Malays.

Badulla district is one of seven districts where there are large numbers of estates, covering an extent of 39,752 hectares. The plantation population of 157,643 represents one fifth of the whole population in Badulla district. There are 75-tea plantations, each having a land area ranging from 140 to 1,800 hectares and a population ranging from 828 to 4,447 .

\section{Design and Sample Selection}

Cross sectional descriptive study using mixed methods in Badulla District in Sri Lanka. The study was done in three stages, 1. Strategic Assessment, Action Research (Intervention) and 3.Evaluation. Number of postnatal mothers to be selected to the sample from each $\mathrm{MOH}$ area was guided by the births reported by the Plantation Human Development Trust for 2003. From the fifteen $\mathrm{MOH}$ areas in the Badulla district thirteen $\mathrm{MOH}$ areas have estates and from this thirteen only ten $\mathrm{MOH}$ areas had births reported for 2003. These ten $\mathrm{MOH}$ areas where births were reported in 2003 were selected for the study.
The number of mothers to be selected from each $\mathrm{MOH}$ area was proportionate to the percentage of deliveries of the year 2003 in each MOH area.

\section{Data Collection}

An interviewer administered questionnaire was administered to 452 randomly selected plantation postpartum mothers at the assessment stage (pre intervention).

Self-administered questionnaire was the instrument of data collector from the nursing officers (the care giver) and sixty were selected randomly.

Intervention: At the Action research stage in depth interviews and group discussions were held to elicit indepth understanding on alcohol use by plantation postpartum mothers. A Behavior Change Communication process (BCC) was carried out to address the behavior of alcohol intake in the postpartum period.

Evaluation: Post intervention assessment was conducted by repeating the questionnaire survey after 6 months on 205 postpartum mothers who had undergone the BCC and sixty nursing staff who were given awareness on BCC.

\section{Results}

The mean age of the mother at birth of the first child was 23.8 years in the pre-intervention sample. There were seventy-three primi gravid and age of the mother at birth of the first child was 23.9 years in the postintervention sample. There was no significant difference of the mean age at the first birth in the two samples ( $p=$ 0.43) (Tables 1-6). Other than the income level of the post-partum mothers there was no significant difference of the two samples taken at the Assessment (pre intervention).

\begin{tabular}{|c|c|c|c|c|c|c|}
\hline \multirow{2}{*}{ Variable } & \multicolumn{2}{|c|}{ Assessment stage $n=452$} & \multicolumn{2}{|c|}{ Evaluation stage $n=205$} & \multirow{2}{*}{$\chi^{2}$} & \multirow[b]{2}{*}{$\mathbf{p}$} \\
\hline & No & $\%$ & No & $\%$ & & \\
\hline \multicolumn{7}{|c|}{ Age (years) } \\
\hline$\leq 18$ & 21 & 4.6 & 6 & 2.9 & & \\
\hline $19-35$ & 407 & 90 & 195 & 95.1 & 5.14 & 0.07 \\
\hline$\geq 36$ & 24 & 5.3 & 4 & 1.9 & & \\
\hline \multicolumn{7}{|c|}{ Ethnicity } \\
\hline Sinhalese & 31 & 6.9 & 18 & 8.8 & & \\
\hline Sri Lankan Tamil & 8 & 1.8 & 6 & 2.9 & & \\
\hline Indian Tamil & 406 & 89.6 & 175 & 85.4 & 3.26 & 0.35 \\
\hline Moor & 7 & 1.5 & 6 & 2.9 & & \\
\hline \multicolumn{5}{|c|}{ Religion } & & \\
\hline
\end{tabular}




\section{Journal of Quality in Health Care \& Economics}

\begin{tabular}{|c|c|c|c|c|c|c|}
\hline Buddhist & 36 & 8 & 21 & 10.2 & 6.2 & 0.18 \\
\hline Hindu & 387 & 85.6 & 170 & 83 & & \\
\hline Islam & 5 & 1.1 & 7 & 3.4 & & \\
\hline Roman Catholic & 16 & 3.5 & 5 & 2.4 & & \\
\hline Other Christian & 8 & 1.8 & 2 & 1 & & \\
\hline \multicolumn{7}{|c|}{ Family Type } \\
\hline Nuclear & 184 & 40.7 & 74 & 35.9 & 1.07 & 0.3 \\
\hline Extended & 268 & 59.3 & 131 & 64.1 & & \\
\hline \multicolumn{7}{|c|}{ Educational status } \\
\hline No formal education & 53 & 11.7 & 19 & 9.3 & 3.82 & 0.28 \\
\hline Grade 1-5 & 141 & 31.2 & 53 & 25.9 & & \\
\hline Grade 6-10 & 175 & 38.7 & 87 & 42.4 & & \\
\hline Passed G.C.E(O/L) or above & 83 & 18.4 & 46 & 22.4 & & \\
\hline \multicolumn{7}{|c|}{ Reading ability } \\
\hline Can read easily & 192 & 42.5 & 93 & 45.6 & 2 & 0.368 \\
\hline Read with difficulty & 135 & 29.9 & 66 & 32.1 & & \\
\hline Cannot read at all & 125 & 27.6 & 46 & 22.3 & & \\
\hline \multicolumn{7}{|c|}{ Family Income } \\
\hline Below Rs. 2500 & 36 & 8 & 5 & 2.4 & 13.42 & $<0.001$ \\
\hline Rs.2501-Rs.4500 & 264 & 58.4 & 105 & 51 & & \\
\hline Rs.4501-Rs.6000 & 152 & 33.6 & 95 & 46.6 & & \\
\hline
\end{tabular}

Table 1: Socio-demographic profile of plantation mothers in the two samples.

\begin{tabular}{|c|c|c|c|c|c|c|}
\hline \multirow{2}{*}{ Variable } & \multicolumn{2}{|c|}{ Pre-intervention sample $\mathrm{N}=452$} & \multicolumn{2}{|c|}{ Post intervention sample $\mathrm{N}=205$} & \multirow{2}{*}{$\chi^{2}$} & \multirow{2}{*}{ p value } \\
\hline & No & $\%$ & No & $\%$ & & \\
\hline \multicolumn{4}{|c|}{ Place of delivery } & & & \\
\hline General /Base Hospital & 227 & 50.3 & 103 & 50.3 & & \\
\hline District /Peripheral unit & 96 & 21.2 & 49 & 23.9 & & \\
\hline Rural estate hospital & 40 & 8.8 & 20 & 9.8 & 1.6 & 0.668 \\
\hline Estate/ EMH ${ }^{\mu}$ & 77 & 17 & 33 & 16 & & \\
\hline Home $^{\mu}$ & 12 & 2.7 & 0 & 0 & & \\
\hline \multicolumn{4}{|c|}{ Mode of delivery } & & & \\
\hline Normal Vaginal & 400 & 88.5 & 167 & 81.6 & & \\
\hline $\mathrm{LSCS}^{\beta}$ & 47 & 11.5 & 38 & 18.4 & 5.9 & 0.015 \\
\hline Forceps/ ${ }^{\circledR}$ Vacuum & 5 & 1.1 & 0 & 0 & & \\
\hline
\end{tabular}

${ }^{\mu}$ numbers were amalgamated ${ }^{\beta}$ numbers were amalgamated

*Five twin deliveries † Fishers exact test

Table 2: Distribution of postnatal mothers according to the place and mode of delivery.

\begin{tabular}{|c|c|c|c|c|c|c|}
\hline \multirow{2}{*}{ Variable } & \multicolumn{2}{|c|}{ Pre-intervention sample $n=457^{*}$} & \multicolumn{2}{|c|}{ Post intervention sample $\mathrm{n}=205$} & \multicolumn{2}{|c|}{\begin{tabular}{|l|l|}
$\chi^{2}$ & P value \\
\end{tabular}} \\
\hline & No & $\%$ & No & $\%$ & & \\
\hline Non Asphyxiated Live Birth $\mu$ & 424 & 92.8 & 195 & 94.7 & & \\
\hline Asphyxiated Live Birth ${ }^{\mu}$ & 30 & 6.6 & 10 & 5.3 & - & $0.55^{\dagger}$ \\
\hline Still birth & 3 & 0.6 & 0 & 0 & & \\
\hline
\end{tabular}

Table 3: Distribution of postnatal mothers according to the delivery outcome.

Almost ninety three percent of plantation mothers in the pre-intervention sample gave birth to a nonasphyxiated live baby. Almost $7 \%$ gave birth to an asphyxiated live baby and $0.6 \%$ was stillbirths. There were no stillbirths in the post-intervention sample. There 


\section{Journal of Quality in Health Care \& Economics}

is no significant difference in outcome of delivery in the two samples $(\mathrm{p}=0.55)$

\begin{tabular}{|c|c|c|c|c|}
\hline \multirow{2}{*}{ Characteristic } & \multicolumn{2}{|c|}{ Pre-intervention sample $n=60$} & \multicolumn{2}{|c|}{ Post-intervention sample $n=60$} \\
\hline & No & $\%$ & No & $\%$ \\
\hline \multicolumn{5}{|c|}{ Category of staff } \\
\hline \multicolumn{5}{|c|}{ Government } \\
\hline Medical officer & 7 & 11.6 & 7 & 11.6 \\
\hline Nurse/sister & 12 & 20 & 12 & 20 \\
\hline Gov Midwife & 21 & 35 & 21 & 35 \\
\hline \multicolumn{5}{|c|}{ Plantation } \\
\hline Estate Midwife & 20 & 33.4 & 20 & 33.4 \\
\hline \multicolumn{5}{|c|}{ Years of service } \\
\hline$<5$ years & 14 & 23.3 & 12 & 20 \\
\hline$>5$ years & 46 & 76.7 & 48 & 80 \\
\hline
\end{tabular}

Table 4: Distribution of the postnatal ward staff by category an years of service.

A self-administered questionnaire was given to a sample of randomly selected postnatal ward staff. There were 60 participants each at the pre-intervention and post-intervention stages. From the government sector there were 7 medical officers, 12 nursing officers / nursing sisters and 21 midwives (Table 5). From the plantations, 20 plantation midwives were selected in the pre and post-intervention samples. In the pre- intervention sample, $23.3 \%$ were with less than 5 years' experience and $76.7 \%$ with more than 5 years' experience.. In the post-intervention sample, there were $20.0 \%$ with less than five years' experience and $80.0 \%$ with more than 5 years of service experience. At the Action Research stage all staff in the selected hospitals was given a behavior Change Communication on prevention of alcohol on the postpartum period.

\begin{tabular}{|c|c|c|c|c|c|c|}
\hline \multirow{2}{*}{ Variable } & \multicolumn{2}{|c|}{ Pre-intervention $\mathbf{n = 6 0}$} & \multicolumn{2}{|c|}{ Post-intervention $\mathbf{n = 6 0}$} & \multirow{2}{*}{$\chi^{2}$} & \multirow{2}{*}{ P value } \\
\cline { 2 - 5 } & No & $\mathbf{9}$ & No & $\mathbf{\%}$ & & \\
\hline Alcohol not to be taken & 35 & 58.5 & 57 & 95 & 20.54 & $<0.001$ \\
\hline
\end{tabular}

Table 5: Advice by postnatal ward staff on alcohol pre- and post-intervention.

Thirty five nursing staff $(58.5 \%)$ had advise on adverse effects of alcohol to the plantation mothers after delivery in the pre-intervention sample it increased to 57 nurses $(95 \%)$ at the post intervention assessment ( $p$ $<0.001$ ) after the BCC process. Alcohol intake reduced to $19.5 \%$ in the post-intervention sample. This showed a significant difference $(\mathrm{p}<0.001)$. From the mothers who had taken alcohol at the assessment stage, majority has taken within a week. This was significantly reduced at the evaluation stage $(\mathrm{p}<0.001)$. In the evaluation stage of the mothers who took alcohol, the majority had taken after 7 days of delivery $(p<0.001)$. Of the plantation mothers who took alcohol in the postnatal period, almost 99\% took alcohol with related to breast-feeding in the preintervention sample. The use of alcohol with related to breast-feeding reduced significantly in the postintervention sample $(\mathrm{p}<0.001)$.

\begin{tabular}{|c|c|c|c|c|c|c|c|}
\hline \multirow{2}{*}{ Variable } & \multicolumn{2}{|c|}{$\begin{array}{c}\text { Pre- } \\
\text { intervention=452 }\end{array}$} & $\begin{array}{c}\text { Post-intervention } \\
\mathbf{n = 2 0 5}\end{array}$ & $\mathbf{\%}$ Diff: & \multirow{2}{*}{ Z } & \multirow{2}{*}{ P value } \\
\cline { 2 - 6 } & $\mathbf{N o}$ & $\mathbf{9}$ & $\mathbf{N o}$ & $\mathbf{\%}$ & $\mathbf{\%}$ & & \\
\hline Taken alcohol in postpartum period & 286 & 63.2 & 40 & 19.5 & 43.8 & 10.32 & $<0.001$ \\
\hline Just after the child birth & 4 & 1.4 & 1 & 2.5 & 1.1 & 0 & 1 \\
\hline Within one week of delivery & 227 & 99.7 & 3 & 7.5 & 89.4 & 14.99 & $<0.001$ \\
\hline After one week of delivery & 5 & 1.7 & 36 & 90 & 88.3 & 15.54 & $<0.001$ \\
\hline Alcohol consumption Related to Breast Feeding & 280 & 98.9 & 8 & 20 & 78.9 & 14.73 & $<0.001$ \\
\hline
\end{tabular}

Table 6: Comparison of postpartum mother taking alcohol before and after intervention. 


\section{Journal of Quality in Health Care \& Economics}

$63.2 \%$ in the pre-intervention sample had taken alcohol during the postnatal period. In the focus group discussions following reasons were identified for postpartum alcohol intake. At the action research stage following were elicited through qualitative data collecting techniques.

"Alcohol was given as a medicine." "A table spoon or two for mother's tummy aches, the wound in the stomach heels and if mother takes before breast feeding it would be helpful for neonate's tummy aches, alcohol was given when mother is given chicken, when she takes a bath to avoid catching the cold, as a stimulant for letting down the milk and given when the mother seems to be sad or unhappy".

\section{Discussion}

Traditionally, the postpartum period is supposed to end at six weeks after birth. Research on postpartum period is very scanty (WHO 1998a). This research focused on the response of a health care system to the needs and challenges of the postpartum period in a multiethnic and multicultural society, "the plantation population in Badulla District". The "Plantation population" in Sri Lanka is considered underprivileged, according to their socio economic background The DHS 2016 shows that: percentage of Households with improved source of drinking water by residence 99\% urban 91\% rural and only $43 \%$ in estates(plantation) (DHS 2016), Households with no electricity $1.3 \%$ urban 3.3\% Rural, and in $4 . \%$ estates (plantation). Residence by Lowest quintile urban $7.6 \%$ rural $19.8 \%$ and in the estate (plantation) it is $70.8 \%$. DHS (2016) No schooling: urban $2.6 \%$ rural $4 \%$ estate plantation 14.5\%. These DHS indicators in 2016 (The last DHS survey in Sri Lanka) shows that the plantation sector is still deprived in Sri Lanka.

The study design was a-static group comparison design (cross-sectional study) and took the form of "Before-after study". Such a study design is considered as a "pre-experimental" design rather than a quasiexperimental because neither control group nor randomization is practiced. Pre-test is being the "before" or "pre-intervention" and post-test is being the "after" or "post-intervention".

The immediate postpartum period: is the period 6 to 24 hours after delivery, the period in which the mother is usually expected to be in a maternity ward under ward staff care.
Socio - demographic factors of the postpartum plantation mother: There was no significant difference of the 452 postpartum mothers who participated at the preintervention stage and the 205 mothers who participated at the post-intervention stage in regard to socio demographic factors. The only difference was the economic condition which can be contributed to the pruning season where the labor force is curtailed to the minimum. Majority of mothers in the study were Indian Tamils by ethnicity and Hindu by religion. Age of the mothers who participated in the study varied from 17 to 44 years. The mean age of the mother at birth of the first child was around 23 years which is almost equal to the Demographic Health Survey (DHS 2016) which was 23.7 Extended families in this study were $59.3 \%$ in the assessment stage and $64.1 \%$ in the evaluation stage, but it was only $31 \%$ for the DHS (2000) survey. The difference may be attributed to the fact that this study covers the postpartum period of the mother and, it is well observed traditionally that the maximum family support is given during this period.

It is a well-accepted fact that educating a woman would reap high returns when it effects on family welfare, particularly on the health and nutritional levels of children are taken in to consideration. In the assessment and evaluation stage, $11.7 \%$ and $9.3 \%$ plantation postpartum mothers have never attended school. This figure is DHS (2016) $14.5 \%$. The alarming finding in this study is that $27.7 \%$ from the pre-intervention sample and $22.3 \%$ from the post intervention sample could not read at all the daily newspaper given in their language, and only $42.5 \%$ and $45.6 \%$ of the plantation postpartum mothers in the two samples, respectively, could read the paper easily only. In the DHS 2016 it was even lower only $38.9 \%$ in the estate/plantation could read a whole sentence. This low literacy rate of the plantation community urges paying more attention to this fact in planning health interventions and providing special care to the plantation mother.

DHS 2016 shows that plantation estate population consume alcohol more than their counterparts Urban $34.6 \%$ Rural $37.4 \%$ estate $44.9 \%$ drink alcohol. Habits of the plantation mother are also culturally influenced. In the focus group, discussions with community leaders and in-depth interviews with a mother and a grandmother showed facts regarding taking alcohol during postpartum period are a cultural practice with the estate community. Majority (63.4\%) of the postpartum mothers in the study population had taken alcohol. In the literature, it has been documented that this habit of taking alcohol by 


\section{Journal of Quality in Health Care \& Economics}

postpartum mother is prevalent in other communities $[7,8]$. Routine obstetric care often does not identify these women. In the action research stage ward staff were trained in Behavior Change Communication (BCC) and made aware to speak with the postnatal mother regarding the negative effects of alcohol on a neonate's brain. The message has been well conveyed, as it was observed in the evaluation that only $19.4 \%$ had taken alcohol in the postnatal period after the intervention with a significant improvement. Only 58.5\% ward staff in the preintervention sample advised plantation mother not to take alcohol in the postpartum period. It significantly improved to $95 \%$ after the intervention. After the intervention ward staff advising mothers in the plantation not to take alcohol significantly improved $(\mathrm{P}<0.001)$ $[9,10]$. However, a study has indicated that lactating women, who were either encouraged to drink or received no advice at all about alcohol, reported drinking significantly more than the women who were advised not to drink. A hundred different customs, some beneficial but some harmful, are at work. Implanting scientific ideas in non-scientific cultures meets with resistance. All who work in primary health care must seek to understand peoples' beliefs about the causation of disease and its cure. The basic elements of social anthropology and Behavior Change Communication must be inculcated in their training programs so that those who work in the health service can do so with empathy. Moreover, success often depends upon modifications outside the purely medical field so that knowledge of the community in a wider sense is needed. The community should be studied for its folk medicine, economics, family structure, politics and religion, and for its systems of value and prestige. "Behavior Change Communication (BCC)" or "Social and behavior change communication (SBCC) or "Communication for Development (C4D), can be used as the vehicle for this community empowerment.

\section{Conclusion}

This study shows that Behaviour Change Communication process (BCC) can significantly reduce alcohol use of plantation postpartum mothers, which will improve the health of the plantation mother and the child.

\section{Outcome and how the Work was Applied}

Addressing the Plantation Mothers behavior changes through BCC process with the Plantation trust and Health Promotion Bureau in Sri Lanka where the Principal Investigator became the Director in 2012.

\section{Acknowledgement}

Dr. I. Hettiarachi (Earlier Director PHDT), Director and staff at the PHDT Badulla and, all Managers and Midwives in the plantations during data collection my data collectors Dr Velaudan and Mrs. Munaweera (RSPHNO), All who participated in the study.

\section{References}

1. UNESCO (2008) Communication for Development and Social Change. Edited by Jan Servaes. SAGE Publications India Pvt Ltd ISBN: 978-0-7619-3609-1 (PB) pp: 1-429.

2. Sunderlal, Adarsh, Pankaj (2016) Text book of community medicine, 4th (Edn.), chapter 2, pp: 3-48.

3. Bowen A, Tumback L (2010) Alcohol and breastfeeding: Dispelling the myths and promoting the evidence. Nurs Womens Health 14(6): 456-461.

4. Mennella J (1997) Infants suckling responses to the flavor of alcohol in mother's breast milk. Alcoholism Clinical and Experimental Research 21(4): 581-585.

5. World Health Organization (2001) Healthy eating during pregnancy and breastfeeding. pp: 1-26.

6. Laantera S, Pietila A, Polkki T (2010) Knowledge of breastfeeding among pregnant mothers and fathers. J Perinat Neonat Nurs 24(4): 320-329.

7. (2018) Center of Disease Control and Prevention (CDC) Breast feeding.

8. Aryal K, Thapa N, Mehatha S, Thapa P, Alvik A, et al. (2016) Alcohol Consumption during Pregnancy and Postpartum Period and its Predictors in Sindhupal chowk District, Nepal September 2016 Journal of Nepal Health Research Council 14(34): 143-153.

9. Chapman SL, Wu LT (2013) Postpartum substance use and depressive symptoms: A review. Women Health 53(3): 479-503.

10. Sri Lanka Demographic and Health Survey (2016) Department of Census and Statistics, ICF International. Sri Lanka pp: 1-16.

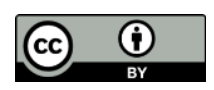

Copyright@ Rajapaksa Hewageegana NS and Samarage S.
Rajapaksa Hewageegana NS and Samarage S. Successful Behavior Change Communication Process to Reduce Postpartum Alcohol Intake. J Qual Healthcare Eco 2019, 2(4): 000133. 